\title{
Life saving use of ECMO in an obstetric patient with massive hemorrhage following uterine atony: a case report
}

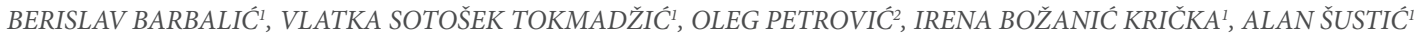

${ }^{1}$ Department of Anesthesiology and ICU, University Hospital Rijeka, Rijeka, Croatia

${ }^{2}$ Department of Gynecology and obstetrics, University Hospital Rijeka, Rijeka, Croatia

Corresponding author:

Alan Šustić

Department of Anesthesiology and ICU

University Hospital of Rijeka

T. Strizica 3. 51000 Rijeka. Croatia

E-mail:alan.sustic@uniri.hr

\section{ABSTRACT}

The aim of this case report is to present the life saving use of extracorporeal membrane oxygenation (ECMO) in an obstetric patient with acute cardiorespiratory collapse following massive bleeding caused by an atonic uterus post partum. A 39-year-old patient, following a spontaneous abortion at 21 weeks of pregnancy, developed uterine atony and massive bleeding and was ultimately referred to the operating room for an emergent hysterectomy. Postoperatively, she was referred to the intensive care unit (ICU) where she developed severe acute respiratory distress syndrome (ARDS) that was successfully treated by employing ECMO. Following discontinuation of ECMO, her treatment was further complicated by a manifest hemolytic transfusion reaction. Although extensive testing was done to establish the cause of this reaction, we were unable to find it. The patient responded well to treatment with erythropoietin (EPO) and corticosteroids as well as a restrictive transfusion regime. This treatment pointed to a possible immune reaction to massive transfusions of blood products. This case demonstrated the importance of early aggressive treatment using ECMO in reversal of life threatening ARDS, as well as the need for a judicious approach when transfusing blood products.

Key words: ECMO (extracorporeal membrane oxygenation), hemorrhagic diathesis, obstetric patients

\section{INTRODUCTION}

The treatment of patients with cardiorespiratory failure frequently requires the use of extracorporeal membrane oxygenation (ECMO). There have been clear demonstrations of its benefit in the general population of patients, with various indications. (1)

Successful use of ECMO immediately postpartum has been reported in several case studies in obstetric patients with various indications. (2-8)

In this report, we present a complex case of an obstetric patient with massive hemorrhage after a spontaneous abortion at 21 weeks of gestation. There was implementation of ECMO, as a life saving measure, which allowed the recovery of the patient's cardiorespiratory functions.

\section{CASE PRESENTATION}

A 39-year-old female patient, at 21 weeks of gestation of a previously uncomplicated pregnancy, was referred to the delivery room due to suspected leakage of amniotic fluid. The first ultrasound exam revealed a healthy live female fetus with biometry corresponding to 21 weeks of gestation. Contractions appeared, amniotic membranes ruptured spontaneously, and five hours later, a dead fetus weighing $480 \mathrm{~g}$ was miscarried. Placental and decidual tissues were removed instrumentally during short intravenous anesthesia. Massive vaginal bleeding and hemodynamic insta- bility complicated the early postpartum period; therefore, the patient was subjected to repeated curettage to establish control of bleeding. Bleeding continued, until finally, the patient underwent emergent transabdominal hysterectomy.

Preoperatively drawn coagulation tests showed the development of severe coagulopathy (DIC). The attending anesthesiologist instituted a massive transfusion protocol. Intraoperatively, the patient received $3480 \mathrm{~mL}$ of packed red blood cells, 2040 $\mathrm{mL}$ of freshly frozen plasma (FFP), and $700 \mathrm{~mL}$ of packed thrombocytes using a rapid infusion system. Despite attempts at hemodynamic stabilization, which besides blood and volume replacement also included a continuous infusion of vasoactive drugs, the patient went into short cardiac arrest twice during the operation and was successfully resuscitated on both occasions. The patient also developed signs of acute respiratory distress (ARDS), manifested by extreme difficulty at maintaining mechanical ventilation and massive alveolar discharge.

She was admitted to the intensive care unit (ICU) postoperatively, where hemodynamic and respiratory instability continued. Hypoxemia developed $(\mathrm{PaO} 2 / \mathrm{FiO} 2$ ratio of 67 on day two with $\mathrm{FiO} 2>80 \%$ ) despite aggressive mechanical respiratory support, and therefore, ECMO (Maquet Cardiohelp; Hirlingen, Germany) was indicated. In addition, due to developing acute renal failure, continuous vena-venous hemodialysis (CVVHD) ((Gambro Lundia; Lund, Sweden) was also needed. 
Throughout the early period, continuing coagulopathy and manifest bleeding further complicated treatment, because of which, massive transfusions were still needed.

During the 8 days of ECMO treatment, the patient achieved adequate respiratory parameters and the system was decannulated. ECMO clinical course is displayed in table 1. After 15 days of treatment, renal function recovered and CVVHD was discontinued.

Sedation was discontinued at day 18 and the patient slowly regained consciousness during the next few days. She fully awoke and was extubated on day 29 of treatment.

However, from day 13 of treatment, we ob- served an increased level of hemolysis and an increase in serum bilirubin levels. This trend continued throughout the following weeks. Direct Coombs tests, performed on several occasions, confirmed the presence of agglutinated antibodies on the surface of erythrocytes. Further diagnostic tests were unable to establish the target of antibody agglutination. Tests done to establish the presence of circulating irregular antibodies were negative on multiple occasions. Following consultations with a hematologist, we attempted plasmapheresis several times. This proved unsuccessful in treating the hemolytic reaction, and on day 33, corticosteroid treatment and application of erythropoietin (EPO) commenced. We also started treatment with Folacin and iron supplements and implemented a restrictive regimen of transfusion therapy.
Ultimately, these treatments proved successful, and on day 40 , we observed a drop in the rate of hemolysis and serum bilirubin levels for the first time. During the remaining 11 days of treatment, the rate of hemolysis, hemoglobin, and hematocrit values slowly normalized.

The patient also underwent several surgical procedures during her ECMO treatment to achieve control of bleeding and evacuate hematomas. These are listed in table 2 .

Finally, on day 55 of treatment, we released the patient to a medical team for air transport to her homeland.

Table 1. Clinical ECMO course.

\begin{tabular}{|c|c|c|c|c|c|c|c|c|}
\hline $\begin{array}{l}\text { Day of ICU } \\
\text { treatment }\end{array}$ & Day 2 & Day 3 & Day 4 & Day 5 & Day 6 & Day 7 & Day 8 & Day 9 \\
\hline $\begin{array}{l}\text { Day of ECMO } \\
\text { treatment }\end{array}$ & Day 1 & Day 2 & Day 3 & Day 4 & Day 5 & Day 6 & Day 7 & Day 8 \\
\hline $\mathrm{pH}$ & 7.17 & 7.47 & 7.45 & 7.39 & 7.55 & 7.50 & 7.50 & 7.47 \\
\hline pCO2 (kPa) & 5.7 & 3.9 & 4.9 & 5.6 & 3.6 & 3.1 & 4.8 & 4.9 \\
\hline pO2 (kPa) & 7.2 & 11.9 & 10.0 & 8.9 & 11.4 & 13.1 & 15.9 & 19.4 \\
\hline $\mathrm{SO} 2(\%)$ & 79.2 & 97.4 & 95.7 & 93 & 97.6 & 98.0 & 98.6 & 99.0 \\
\hline $\mathrm{Hb}(\mathrm{g} / \mathrm{L})$ & 59 & 81 & 74 & 115 & 90 & 84 & 74 & 84 \\
\hline Htc & 0.15 & 0.25 & 0.22 & 0.34 & 0.26 & 0.23 & 0.22 & 0.25 \\
\hline $\begin{array}{l}\mathrm{O} 2(\mathrm{l} / \mathrm{min})- \\
\text { oxy }\end{array}$ & 3.6 & 4.9 & 5.2 & 5.2 & 5.3 & 5.4 & 5.3 & 5.3 \\
\hline FiO2 - oxy & 0.75 & 0.84 & 0.84 & 0.82 & 0.85 & 0.86 & 0.88 & 0.88 \\
\hline RPM & 2200 & 2595 & 2715 & 2700 & 2700 & 2700 & 2380 & 2454 \\
\hline LPM & 3000 & 3540 & 3590 & 3500 & 3600 & 3570 & 3000 & 3160 \\
\hline $\mathrm{ACT}$ & 258 & 155 & 166 & 134 & 153 & 145 & 134 & 149 \\
\hline Heparin & & 9750 i.u. $/ 24 h$ & 14400 i.u./24h & 17500 i.u./24h & 25440 i.u. $/ 24 h$ & 24000 i.u. $/ 24 h$ & 24000 i.u./24h & 28800 i.u. $/ 24 \mathrm{~h}$ \\
\hline Protamine & & & & & & & & 2000 i.u. \\
\hline $\begin{array}{l}\text { FFP (units, } \\
\text { whole day) }\end{array}$ & 11 & 14 & 3 & 0 & 0 & 3 & 10 & 0 \\
\hline $\begin{array}{l}\text { RBC (units, } \\
\text { whole day) }\end{array}$ & 13 & 12 & 6 & 0 & 3 & 8 & 14 & 4 \\
\hline $\begin{array}{l}\text { Platelets (units, } \\
\text { whole day) }\end{array}$ & & 2 & 2 & 1 & 1 & 2 & 5 & 3 \\
\hline
\end{tabular}

ACT, activated clotting time; FFP, Freshly Frozen Plasma units transfused; Hb, Hemoglobin; Htc, Hematocrit; LPM, litres per minute; $\mathrm{RBC}$, Red Blood Cells units transfused; RPM, revolutions per minute; oxy, oxygenator. 
Table 2. Surgical interventions.

\begin{tabular}{ll}
\hline Day of treatment & Type of intervention \\
\hline Day 2 & Chest drainage \\
\hline Day 2 & ECMO Cannulation \\
\hline Day 2 & Emergent decompressive laparotomy \\
\hline Day 3 & Relaparotomy, evacuation of intraabdominal hematoma, tamponade \\
\hline Day 5 & Relaparotomy, drainage and lavage, retamponade \\
\hline Day 7 & Evacuation of intraabdominal hematoma, retamponade \\
\hline Day 8 & Evacuation of intraabdominal hematoma, retamponade \\
\hline Day 9 & ECMO decannulaton \\
\hline Day 10 & Peritoneal lavage and drainage \\
\hline Day 12 & Peritoneal lavage and drainage \\
\hline Day 14 & Peritoneal lavage and drainage \\
\hline Day 16 & Peritoneal lavage and drainage, abdominal wall reconstruction \\
\hline Day 32 & Cystoscopy \\
\hline Day 34 & $\begin{array}{l}\text { Relaparotomy, drainage and lavage, evacuation of intraabdominal } \\
\text { hematoma }\end{array}$ \\
\hline Day 40 & $\begin{array}{l}\text { Relaparotomy, drainage and lavage, evacuation of intraabdominal } \\
\text { hematoma }\end{array}$ \\
\hline
\end{tabular}

\section{DISCUSSION}

Postpartum hemorrhage is one of the leading causes of maternal mortality. According to World Health Organization (WHO) statistics, severe bleeding accounts for $27 \%$ of all deaths in the postpartum period. (9)

Use of ECMO in obstetric patients has been described before in cases such as ARDS, (2) transfusion related acute lung injury (TRALI) following transfusion, (4) amniotic fluid embolism, (3) cardiomyopathy, (5) and for management of cardiorespiratory collapse following massive bleeding. $(6,7)$

In this case, we reached the decision to commence treatment with ECMO very early in the course of treatment, primarily due to severe ARDS. We presumed that cardiac failure and ARDS in this case were the results of hypovolemic shock and subsequent massive volume resuscitation.

Commencing ECMO in a patient with impaired coagulation is linked with risks in worsening the hemorrhagic diathesis. However, according to Extracorporeal Life Support Organization Guidelines, only active intracranial hemorrhage is considered to be a contraindication to ECMO. (10)

Because of the patient's severe condition, and keeping in mind all potential risks in- volved, we attempted ECMO as a life-saving measure. Lamb et al. have shown that there can be successful management of ECMO bleeding complications in patients with primary respiratory failure. (8) According to ECMO guidelines, there are no contraindications of surgical procedures during treatment; in fact, early aggressive treatment targeting potential causes of cardiorespiratory collapse are encouraged. (10)

Bleeding complications in our patient continued throughout and this resulted in continued massive transfusions during early stages of ECMO. CVVHD augmented ECMO treatment due to manifest acute renal failure.

Further treatment, following cardiorespiratory stabilization and recovery of renal function, was complicated by a hemolytic reaction. Initially, we assumed this was due to the extensive volume of extracorporeal circulation involved; however, the trend continued and in fact worsened after discontinuation of extracorporeal support. Later, we assumed this was a result of an immune reaction to large volumes of blood products transfused throughout treatment. Direct Coombs test done on day 10 of treatment seemed to confirm this, as agglutinated antibodies were found on the surface of red blood cells (RBCs). However, further immunologic testing failed to prove the existence of circulating antibodies, i.e., , we were unable to find the target of this immune reaction. This possibly explains why our attempted treatment with plasmapheresis was unsuccessful. However, despite this, the most likely explanation for the continued hemolytic reaction continued to be an immune response of our patient's body to transfused blood products.

Because of this assumed mechanism, we decided to commence treatment with EPO to stimulate erythropoiesis, together with a restrictive regime of blood transfusion, which allowed for lower levels of hemoglobin and hematocrit before transfusing RBCs. Corticosteroid therapy was also started due to this assumed immunologic mechanism. The patient responded well to these treatments and fully recovered.

\section{CONCLUSION}

Despite potential misgivings of commencing ECMO in an actively bleeding patient with impaired coagulation, our case clearly demonstrates that this method has a place in the treatment of acute cardiorespiratory failure. This case has also shown that, when indicated, surgical procedures should be done in such a patient. The treating physicians should always be watchful for possible bleeding complications, and weigh 
the potential risks and benefits before commencing ECMO, as well as any other treatment.
This case also clearly shows the need for a judicious approach when transfusing blood products in such patients.

\section{ACKNOWLEDGMENT}

We would like to thank the patient and her family for kindly agreeing to have her case history shared.

\section{REFERENCES}

1. Marasco SF, Lukas G, McDonald M, McMillan J, Ihle B. Review of ECMO (extra corporeal membrane oxygenation) support in critically ill adult patients. Heart Lung Circ 2008;17 Suppl 4:S41-7.

2. Nair P, Davies AR, Beca J, Bellomo R, Ellwood D, Forrest P, et al. Extracorporeal membrane oxygenation for severe ARDS in pregnant and postpartum women during the 2009 H1N1 pandemic. Intensive Care Med 2011;37:648-54.

3. Ho CH1, Chen KB, Liu SK, Liu YF, Cheng HC, Wu RS. Early application of extracorporeal membrane oxygenation in a patient with amniotic fluid embolism. Acta Anaesthesiol Taiwan 2009;47:99-102.

4. Lee AJ, Koyyalamudi PL, Martinez-Ruiz R. Severe transfusion-related acute lung injury managed with extracorporeal membrane oxygenation (ECMO) in an obstetric patient. J Clin Anesth 2008;20:549-52.

5. Palanzo DA, Baer LD, El-Banayosy A, Stephenson E, Mulvey S, McCoach RM, et al. Successful treatment of peripartum cardiomyopathy with extracorporeal membrane oxygenation. Perfusion 2009;24:75-9.

6. Reyftmann L, Morau E, Dechaud H, Frapier JM, Hedon B. Extracorporeal membrane oxygenation therapy for circulatory arrest due to postpartum hemorrhage. Obstet Gynecol 2006;107(2 Pt 2):511-4.

7. Taiga Itagaki, Mutsuo Onodera, Nao Okuda, Emiko Nakataki, Hideaki Imanaka, Masaji Nishimura. Successful use of extracorporeal membrane oxygenation in the reversal of cardiorespiratory failure induced by atonic uterine bleeding: a case report. J Med Case Rep 2014;8:23.

8. Lamb KM, Cowan SW, Evans N, Pitcher H, Moritz T, Lazar M, et al. Successful management of bleeding complications in patients supported with extracorporeal membrane oxygenation with primary respiratory failure. Perfusion 2013;28:125-31.

9. Maternal Mortality Fact sheet $\mathrm{N}^{\circ} 348$. World Health Organisation [Online] 2014. Available at: http://www.who.int/mediacentre/ factsheets/fs348/en/ [2015-04-03]

10. Extracorporeal Life Support Organisation. ELSO Guidelines for Adult Respiratory Failure [Online]. 2013. Available at: https://www. elso.org/Portals/0/IGD/Archive/FileManager/989d4d4d14cusersshyerdocumentselsoguidelinesforadultrespiratoryfailure1.3.pdf [2015-03-04] 